\title{
AC 2007-734: LESSONS LEARNED FROM THE DEVELOPMENT OF A KNOWLEDGE SHARING SYSTEM (KSS) USED TO DEVELOP AND SUSTAIN A CROSS-DISCIPLINARY OUTREACH APPROACH TO ENGINEERING DESIGN
}

Barry Cumbie, Auburn University

Chetan Sankar, Auburn University

P.K. Raju, Auburn University 


\section{Lessons Learned from the Development of a Knowledge Sharing System (KSS) used to Develop and Sustain a Cross- Disciplinary Outreach Approach to Engineering Design}

The Capstone program is an opportunity for graduating senior students in engineering to apply their classroom knowledge to real-world problems. While the experience from this course is valuable for students in preparation for their careers, an opportunity exists through the use of information technology (IT) to improve the administration of the program while extending the positive aspects of this program to the community at-large and to future students. The use of an IT-based system enables the problems addressed by Capstone students to be preserved and subsequently reused, refined, and built upon to address the problems that arise tomorrow.

This paper relates the details of an NSF-sponsored project that included the development of an IT-based Knowledge Sharing System (KSS) to assist with the capture and proliferation of accumulated student experiences. This project serves as a template for similar efforts and includes the theoretical background and system development methodology used in development. Additionally an overview of the system is presented followed by lessons learned from these efforts. By providing this information the authors hope to encourage the innovative application of IT in Capstone programs at other universities.

\section{Background: Project Overview}

The Auburn Engineering Technical Assistance Program (ATAP) has used their funding from the National Science Foundation (ENG\#0332594) to marshal the diverse resources and interests of different (a) units of a state cooperative extension system, (b) departments of an academic institution, (c) research laboratories, (d) industrial development units of private corporations and government, and (e) manufacturing companies. The partnership, entitled "Initiating and Sustaining Industrial Renaissance through Innovative Partnerships (ISIRP)," is developing an atmosphere of cooperation and building an infrastructure that enables innovations to be readily transferred to industries, while at the same time providing real-world problem solving experience for university faculty members and students. During 2004-2006, the research team visited and worked with (a) 121 companies, (b) 13 county extension agents in Alabama and (c) 1 research organization. The research results from these projects have led to significant savings for the companies due to the innovative engineering solutions that have been applied to their problems. The economic impact to the state of Alabama through this activity is over $\$ 9$ million per year.

A critical component of the ISIRP project is the cross-disciplinary relationship between the engineering and business schools. Management Information Systems (MIS) faculty and students participated by developing an information system that evolved from administrative capturing senior design experiences. The KSS has been deployed not only to support the project but also as a potentially strategic tool that extends the value of engineering Capstone projects by creating a repository of projects to be used by students, 
faculty, and industry for tomorrow's problems. This KSS is based upon knowledge management theory and employed the use of a prototyping system development methodology. This system facilitates a model for symbiotic partnership that enables a sustainable approach to technology transfer, ensuring relevancy in the university while serving the community.

\section{Background: Theory and Methodology}

The development of the KSS follows the information ladder, a theoretical model that describes the stages of learning through five stages: data, information, knowledge, understanding, and wisdom ${ }^{1}$. Currently the Capstone program enables participating students to apply the information and knowledge learned from their classes. For example, students design and build equipment to automate a production process for a business. This experience provides the opportunity to elevate their classroom knowledge toward a higher level of learning in which students apply theories learned in classrooms to solve problems in real-world settings.

Despite the classroom success of the Capstone program, an overall organizational perspective is lacking from the university. The understanding achieved by individual students fails to be retained at the organizational level. Instead, the university simply retains administrative information (e.g. enrolled students and grade earned). While this information is important, the opportunity exists to preserve a higher level of knowledge throughout the organization. Organizational learning is a concept in the growing field of knowledge management which describes organizational efforts to capture and retain knowledge for subsequent reuse, i.e. to prevent re-inventing the wheel for each new problem $^{2}$. The theoretical tenants of knowledge management include the identification of knowledge within an organization so that it may be preserved and deployed in a manner to empower knowledge as a strategic asset.

The outreach mission of most universities seeks to transfer scientific research outward to the community to address practical problems. Recognizing the dual mission of education and outreach, the principles of knowledge management can be applied to the Capstone program to address both goals simultaneously. In this respect, the understanding achieved by individual students could be preserved at the organizational level and used for outreach activities. The result would be the university retaining more than just administrative information, but actionable engineering knowledge that can then be transferred to the community.

In an effort to achieve the goal of transferring knowledge from the Capstone program to the community, the prototyping system development methodology was adopted. This methodology calls for an initial gathering of system requirements, the development of an initial prototype, a review by the end-users, and a revision for the next version of the prototype $^{3}$. This methodology continues cyclically until the prototype reaches an acceptable level of completeness. Each iteration yields a new version of the prototype and results are produced more quickly than other system development methodologies. 
This method was chosen as the best fit for the university research and design environment. This environment is characterized by student workers, typically without commercial experience, who work on a project on a limited basis because of other academic responsibilities. Students have a high turnover rate, since their schedules change each semester. The prototyping methodology suits this environment well, allowing the student participants to produce results within their time constraints and for the transition of students to coincide with each new prototype version.

An additional benefit of the prototyping methodology is the quickness in which a result, albeit incomplete, is produced. For exploratory research projects such as this each prototype iteration allows for the reevaluation of the project scope or direction. The reevaluation process permits an organic growth of the system, that is, one in which the requirements are flexible enough to accommodate the needs of a changing environment. The next section describes the system in more detail.

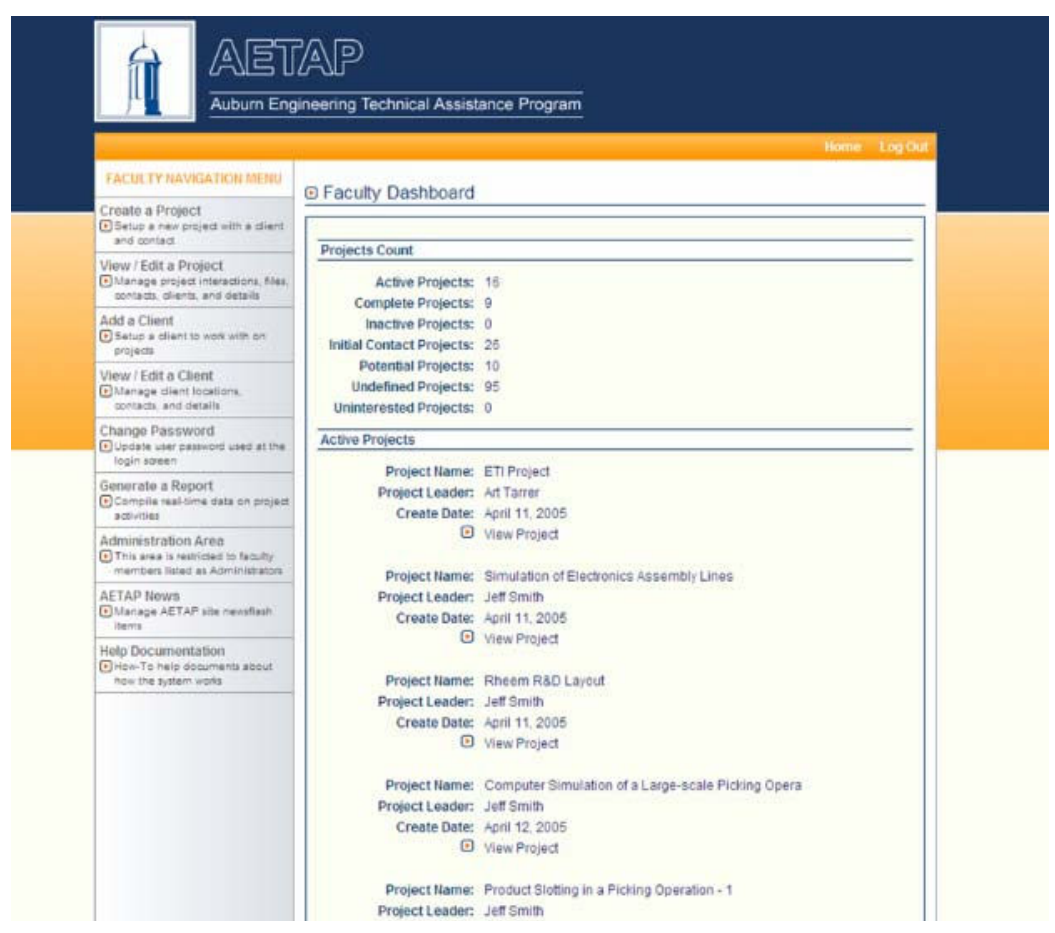

Figure 1 - KSS Faculty Dashboard

\section{The Knowledge Sharing System (KSS)}

The current version of the KSS is accessible from a web browser over the Internet and features a rich informational repository of engineering projects. Participating faculty can access the web site and sign on to access the many features. The sign on features includes security levels to restrict what information a particular user can access. Administrators can create new users or maintain the system and faculty are able to view and edit their projects. Upon successfully signing on, faculty (or delegated students) are directed to the KSS' Faculty Dashboard (Figure 1), a summary of project information 
that includes the cumulative number of active and potential projects. In addition to Capstone projects the KSS also stores information for other types of projects such as faculty consultations and joint projects between faculty and (usually graduate) students.

From the dashboard view, users are able to initiate or edit a project which includes the clients associated with each project. The clients are a vital to the high educational quality of the Capstone program as they provide real engineering problems to be addressed by student teams and benefit by receiving innovative solutions. The KSS enables the close tracking of clients to ensure that a client who comes in contact with the university will not be overlooked and that communications are both timely and thorough. In this way, clients are available to provide the best possible projects for the Capstone students.

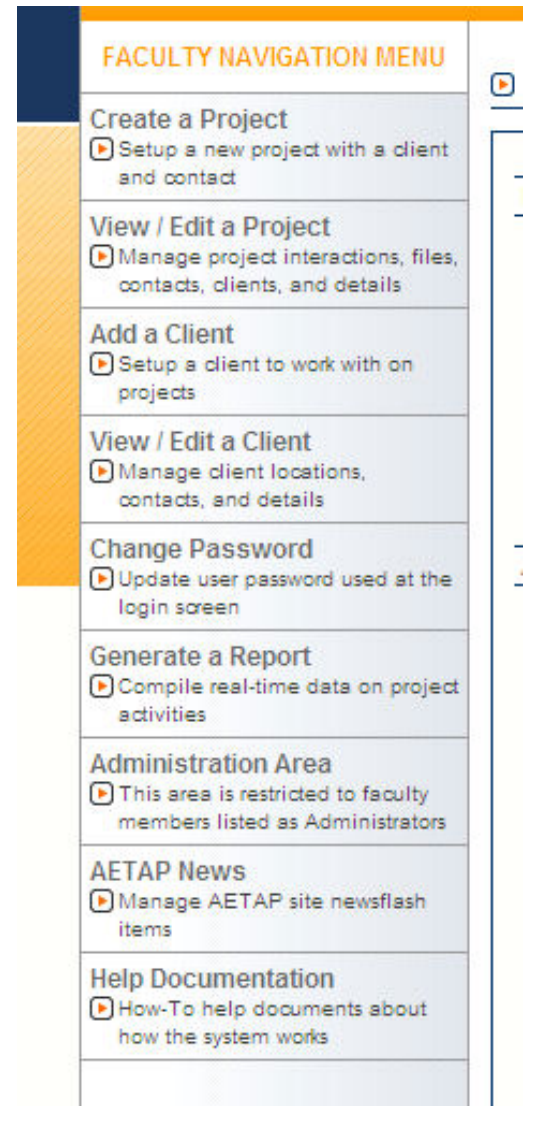

Figure 2 - KSS Menu
The menu of the left side of Figure 1 is shown up close in Figure 2 and illustrates the additional features that users can access. These features include the ability to generate managerial reports, administer the system, and post news stories to the website. Generating reports is useful to monitor the progress of projects, including reporting the affects of these projects, e.g. an economic impact of $\$ 9$ million dollars saved by participating companies to date. This information is useful to attract new partners and obtain sponsorship by clearly articulating the impact of the Capstone program. The administration area allows for system administers to assign permissions to users and to change the actual categories that tracked in the system. For example, the participatory role of the clients can be modified as shown in Figure 3. This allows for the system to be dynamic and changes do not require a deployment of a new version. News announcements are also managed from this menu. Users are able to post news about their projects to a publicly accessible web site. This is a good way to showcase Capstone project successes and communicate with the community.

Again from the dashboard, each project can be examined at a closer level: details can be viewed or edited such as clients and contact information, interactions between clients and faculty or students are documented, and the outcomes of the project are recorded. These current features of the KSS are the foundations of an IT platform capable of supporting a knowledge repository and encouraging the preservation of organizational learning. Referring to the information ladder, the KSS is an engine to collect a solid base of data that is then organized well. 


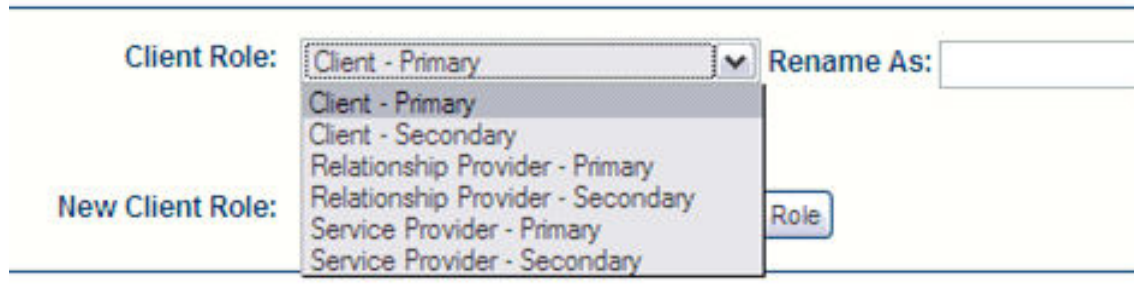

Figure 3 - KSS Administration Area Example

The development in progress includes the additional features of increased availability of the KSS to participating clients and the engineering community and the ability to upload multimedia project documentation such as pictures, presentations, videos, and technical documentation. Once stored in the KSS, the project information together with the knowledge captured in the technical project documentation will be searchable, allowing potential clients to see the results produced by Capstone projects for other companies. At the very least the system will provide a means to locate an expert in the problem area. At most, as the project documentation grows, those in the engineering community will be able to search the KSS repository and possibly find a documented project that provides the expertise to solve a problem themselves.

\section{Lessons Learned}

The functionality of the KSS might have been achieved quicker and perhaps built better by IT professionals; however, the cost of professional services was not budgeted for in this project. By employing the talents of students a usable and useful system was developed while simultaneously developing the skills of the students to be competitive in the marketplace or the next level of education. The involvement of students created an environment of all-around learning from which the following lessons about developing the KSS to support the Capstone program were learned:

\section{Create win-win cross-disciplinary relationships}

Developing an IT system is a resource intensive effort and is many times cost prohibitive for a single university department. The relationship between the engineering and business schools at Auburn University allowed for the development of the KSS to occur while simultaneously benefiting the students and faculty of each department. MIS students were able to experience their own Capstone experience by applying their classroom skills to a real world problem.

\section{Integration with Design Curriculum: Constantly Involve Students}

A key to the development of the KSS was the involvement of students, both business and engineering at all levels. Students participated in weekly meetings, talking with potential users of the system, and presenting prototypes at conferences and workshops. In this way, learning was maximized by allowing students to go beyond working behind doors and interact with contacts from the industry. 
The integration of the KSS into design curriculum was facilitated by the constant involvement of students who could at once contribute their ideas and opinions and also act as advocates of the system to other students.

The downside of student turnover was mitigated by recruiting students to work with those with experience on the project. In this way departing students could explore continuing their education and involvement with the project by applying to masters and doctoral programs. Furthermore, a solid transition between departing and entering students was established. This lesson was learned out of the frustrations from students not being able to continue the work of previous students and having to start anew.

Engineering students were involved not only in Capstone projects but also participated in the development and especially the testing of the KSS. The information collected by the KSS allowed for students to be matched with clients from their home counties. This approach seeks to accomplish a side goal: the retention of engineers in the local communities.

\section{Don't try to swallow the elephant all at once}

Developing a customized IT system is no small effort, yet the usefulness of the end product can be worth the effort. The goals for the KSS were set high and the student development teams were excited at the possibilities that may come. While enthusiasm was welcomed among the development team, too much led to unnecessarily high expectations.

The development team of the KSS began trying to solve all the problems at once. Soon after, the basic functionality of the system was being neglected to spend time on ideas for the next version of the prototype. One example is when the development of the system was halted so that paper-based forms could be designed and distributed to the engineering faculty to report about their current engineering design projects. This was a step backward from the goals of creating an online IT-based system. In the end, the project would have been better served to start small and progress steadily upward.

The information ladder provides a guideline of how to approach a project like the KSS. By trying to start at the knowledge level of the ladder and foregoing the data and information levels, a solid foundation to base any knowledge did not exists. It was only be reverting back to the 'data' level by creating a paper-based system to collect the data could the information level be achieved by creating a dynamic IT-based system to organize the data into useful information. At this point, the accumulation of knowledge can be confidently addressed from a solid platform that is the current version of the KSS.

\section{Integration of Theory with Practice}

The ongoing success of the KSS is partially attributed to the integration of the theoretical tenants of knowledge management, i.e. the information ladder, with the practice of the prototype systems design methodology. Not only is the prototyping methodology a good 
fit for a university research environment that is characterized by frequent student turnover and emerging knowledge, but it also is a good fit for climbing the rungs of the information ladder. The iterative process of prototyping is conducive to a flexible, organic system growth in which the initial system versions collects data and is followed by increasingly sophisticated versions which organize the data into useful information and eventually leverage the information to transfer knowledge via outreach activities.

\section{Own your technology}

The development of the KSS had to overcome maturation from a proof-of-concept prototype to a production system. At the early stages, the computer hardware used in development was connected to a departmental network and managed by faculty members to maximize the availability of the system. After the system became compromised from malicious users via the Internet, the system was taken off of the network by administrators. Only after a complete reconfiguration of the hardware could the system be brought back online. This unexpected step took several months away from the primary goals. Essentially, as the system matures so to must the consideration of ownership. While readily available university resources are good for initial research, they may not be appropriate to host systems that could require around-the-clock access. Currently, the system is hosted by the College of Engineering information technology division.

\section{Conclusion}

The overview of the KSS and the lessons learned are intended to encourage the innovative use of IT to enhance engineering design curricula at Auburn University and other institutions. The development of the Knowledge Sharing System (KSS) occurred through the cross-disciplinary relationships between engineering and business faculty and students. The KSS' progress was aided by the information ladder which guided prototype system development methodological approach through the data and information stages. Currently the KSS is an informational platform from which the next prototype version can be developed so as to preserve knowledge about the Capstone projects. Currently, the KSS has helped improve the management of clients, thereby ensuring an inflow of quality projects to the Capstone project. Soon the KSS will be a searchable repository of engineering solutions available over the Internet for the benefit of the engineering community.

\footnotetext{
${ }^{1}$ Longworth, N., and Davies, W.K. (1996). Lifelong Learning. London: Kogan Page Ltd.

${ }^{2}$ Davenport, T.H., and Prusak, L. (2000). Working Knowledge: How Organizations Manage What They Know. Boston: Harvard Business Press.

${ }^{3}$ Beck, P., Jiang, J.J. and Klein, G. (2006). Prototyping mediators to project performance: Learning and interaction. Journal of Systems and Software, 79(7), 1025-1035.
} 